\title{
The effect of public space indicators on the rural district's life quality in Kuhdasht county, Iran
}

\author{
Ahmad Roumiani ${ }^{1}, *$, Taghi Ebrahimi Salari², Hamideh Mahmoodi ${ }^{1}$, Mofid \\ Shateri $^{3}$
}

\footnotetext{
${ }^{1}$ Ferdowsi University of Mashhad, Faculty of Letters and Humanities, Department of Geography, Iran

${ }^{2}$ Ferdowsi University of Mashhad, Faculty of Economics and Administrative sciences, Iran

${ }^{3}$ Birjand University, Faculty of Literature and Humanities, Department of Geography and Rural Planning, Iran

* Corresponding author: roumiani.ah@mail.um.ac.ir
}

\begin{abstract}
This article evaluates nine rural districts in Kuhdasht county, Iran, with a population of 3535 between 2013-2016. We address the following two questions: First, what are the most important criteria and effective indicators in the rural population's quality life enhancement? Second, is there any significant relationship between the public space indicators and quality life enhancement in the case study area? Six factors, including perceptual vision, buildings skeletons, culture and communities, activities, social interaction, and the environment from local peoples' perspectives, explained 52.6 percent of the total variable variances. The Friedman test showed a significant difference among criteria of esthetics, semantic-perceptual, and activity-based functional at the alpha level of 0.01 . The fitting growth regression model showed that the positive effect of the public space indicators on the rural population's vitality and dynamism quality enhancement was about 0.723 , indicating a significant relationship between them. It also stated a vital role of public space indicators in the rural population's vitality and dynamism quality enhancement in the study area. The most important indicators were those of economic, social, and cultural dynamism and the body and space indicators.
\end{abstract}

\section{KEYWORDS}

public spaces; rural services; quality life; Kuhdasht county

Received: 8 May 2021

Accepted: 22 June 2021

Published online: 11 October 2021

Roumiani, A., Salari, T. E., Mahmoodi, H., Shateri, M. (2021): The effect of public space indicators on the rural district's life quality in Kuhdasht county, Iran. AUC Geographica 56(2), 205-219

https://doi.org/10.14712/23361980.2021.9

(C) 2021 The Authors. This is an open-access article distributed under the terms of the Creative Commons Attribution License (http://creativecommons.org/licenses/by/4.0). 


\section{Introduction}

In recent decades, the growing concern of traditional landscapes disappearance and emergence of new ones was paramount importance, not only in developing but also in developed countries. This led to fundamental changes in cultural and traditional landscapes namely types, settlements and landscape's identity (Stockdale and Barker 2009; Meeus et al. 1990; Jung and Ryu 2015). Therefore, the traditional landscapes of the villages should be considering and protect globally in interdisciplinary and interdepartmental frames, in order to pave the way for the environment's protection, attraction and cultural identity. Today, considering the change in youths and elderlies' tastes and behaviors, equipping the rural spaces with the standard furniture adaptable to the sociocultural behavior and rural customs have become a necessary issue (Johnson and Glover 2013). Since, the rural perspective with different semantic, applied, and body dimensions is of high significance in rural space visual organization and quality, it is remarkably effective in visual and structural integrity of the buildings, streets, and places constituting the rural space and environment. Thence, these structures caused the villages to be like a living being possess quality life and dynamism providing people with attractiveness and security (Węziak-Białowolska 2016). Therefore, dynamism in villages is vitally important. The purpose of the current study is to investigate the influence of public spaces indicators on the rural population's quality life and dynamism quality enhancement in the focused zone (Beck 2009). This study fills the gap in the literature in a way that not only it studies rural furniture and landscapes but also effective factors on them and their influence on the rural population's quality life and dynamism quality enhancement. This study, aims at answering the following research questions:

1. What are the most important criterions and effective indicators in the rural population's quality life population enhancement?

2. Is there any significant relationship between the public space indicators and quality life enhancement in the focused zone of the study?

\subsection{Scholars' views towards public spaces}

Based on the public connotation of space, the concept of public spaces has been put forward by scholars. Chen Bo believes that public space is the place and carrier for Local people to participate in Economic, Social and cultural life, which has both geographical spatial significance and sociological sense of public spirit and belonging consciousness (Zhong 2020). Moroni and Chiodelli (2014): "Public (state owned) space is the most likely setting for polemical scenes that start conversations about the public good. Public space should not be viewed only as a site for leisure or recreation but also as a place where people can come together to meet as citizens rather than as consumers or clients."

People's public life occurs in urban-rural public spaces in a complex set of forms and functions; accordingly, these spaces must be capable to contain diverse behavior, uses and activities such as shopping, walking, conversation, using the facilities to entertain, relax or even passing the time as daily activities, and also periodic festivities and events (Jalaladdini and Oktay 2012).

These public spaces interpreters discussed how the space and environment affect people, their feeling, and behavior. The discussion of the public spaces' issues categorized into three sections: 1 . Physical characteristics of the spaces; 2 . Activities happening in the spaces; and 3. the definition of space. These are three sections as 'morphological dimension', 'social and functional dimension' and 'perceptual dimension' (Majedi et al. 2014). According to Carmona et al. 2010; Orum and O'Neal 2009, public space performs several functions, including: 1 . Liveability relevance: For example, streets for pedestrian and vehicular movement, parks, hospitals, etc.; these public spaces relate to certain essential aspects of our being individuals with a body (and hence with the need to move through space to reach other places, to sit and rest, to breathe clean air, go jogging, receive medical assistance, etc.); 2. Sociability relevance: For example, squares, sidewalks, etc.; such spaces enable us to meet other people; 3 . Political relevance: For instance, plazas, public halls, etc.; these spaces provide arenas for public debate on civic issues or in which people can demonstrate and protest.

Gehl and Gemzøe (1999) also showed how the public spaces' environment quality affect people's manner and amount of using them. Based on Gehl, public spaces' activities are recognizable in three sections namely necessary, voluntary, and social activities. When a space suffers from a low quality, the necessary activities are the only type happened in it. With the space quality enhancement, not only necessary activities, but also a plethora of voluntary and social activities will be probable to be happen and people will have more tendencies to do them (Gehl and Gemzøe 1999) (Figure 1).

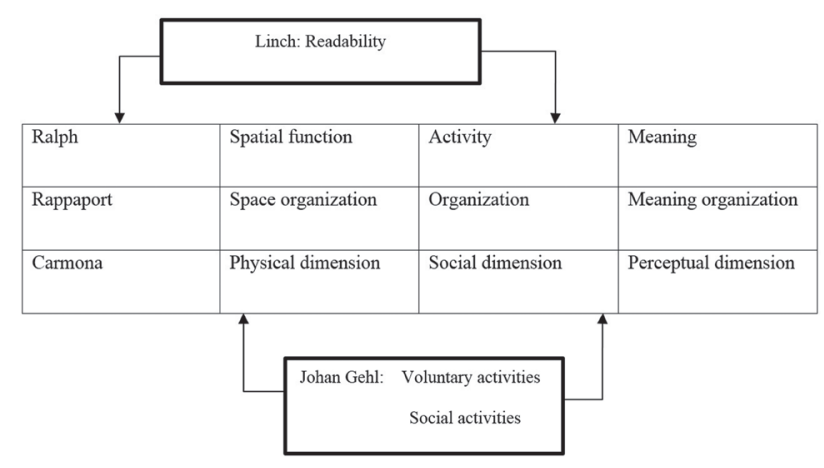

Fig. 1 Relationship between human and space (Gehl and Gemzøe 1999). 
Therefore, besides having physical dimensions, public space is a systematic space and a compound essence, which are intertwine with social time and society's culture in a way that society's sociocultural, economic, and political proportionality play a crucial role in perceiving it (Jung and Ryu 2015). The information provided in Table 1 help to define the public spaces, function measurements, and to understand the public spaces' key characteristics.

Tab. 1 Important approaches in defining and analyzing public spaces.

\begin{tabular}{|c|c|c|c|c|}
\hline Researcher & Definitions & Key characteristics of the approach & Key characteristics & Main functions \\
\hline 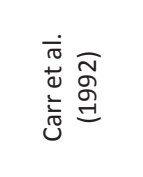 & $\begin{array}{l}\text { - Space is considered as a common } \\
\text { ground on which people connect } \\
\text { the functional and ritual activities } \\
\text { of a society whether in normal life } \\
\text { or periodical festivals }\end{array}$ & $\begin{array}{l}\text { - A connection for the ritual and } \\
\text { functional activities } \\
\text { - A common public space }\end{array}$ & $\begin{array}{l}\text { - Responsible, democratic, and } \\
\text { meaningful }\end{array}$ & \multirow{3}{*}{ 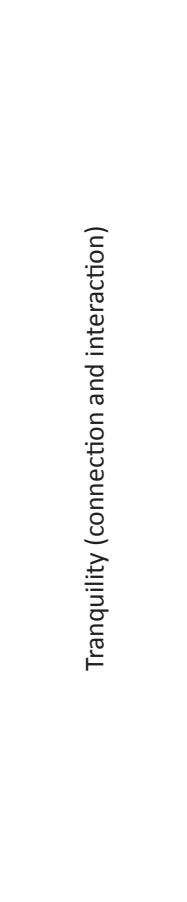 } \\
\hline 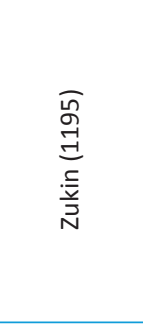 & $\begin{array}{l}\text { - Public spaces regularly choose the } \\
\text { signs and borders of the society as the } \\
\text { topic of discussion } \\
\text { - Public space is a tool for peoples' } \\
\text { social life perspective adjustment }\end{array}$ & $\begin{array}{l}\text { - A key for societies' discussions } \\
\text { - A key for the toleration of the } \\
\text { differences for entering the social life } \\
\text { - A key for interactional situation } \\
\text { - A key for enhancement of the social } \\
\text { life's perspective }\end{array}$ & $\begin{array}{l}\text { - Equity participation, } \\
\text { identification, information and } \\
\text { connection exchange }\end{array}$ & \\
\hline 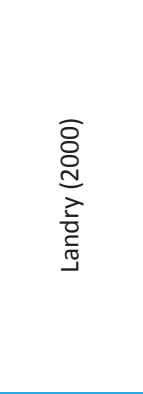 & $\begin{array}{l}\text { - Public space is a complicated, } \\
\text { protean, and instable space } \\
\text { - Public spaces are the reflection of } \\
\text { the human efforts with reference to } \\
\text { which social worlds manufactures are } \\
\text { designed, adapted, and interpreted } \\
\text { - Public spaces are open spaces for } \\
\text { public discussions and displeasure } \\
\text { statement }\end{array}$ & $\begin{array}{l}\text { - A key for public discussion and their } \\
\text { interpretation } \\
\text { - A key for peace and philandrophy }\end{array}$ & $\begin{array}{l}\text { - Cooperation, creating social } \\
\text { networks and institutions }\end{array}$ & \\
\hline 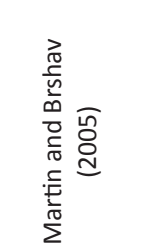 & $\begin{array}{l}\text { - It is a space which includes activities, } \\
\text { events, inspirations and stimulation } \\
\text { enhancing the public space quality } \\
\text { - It is a space that despite the } \\
\text { differences, it functions as a place for } \\
\text { meetings, bazar, and traffic }\end{array}$ & $\begin{array}{l}\text { - A key for the diversification of the } \\
\text { activities } \\
\text { - A key for cooperation and lessening } \\
\text { the differences }\end{array}$ & $\begin{array}{l}\text { - Social partnership and social } \\
\text { network }\end{array}$ & \multirow{2}{*}{ 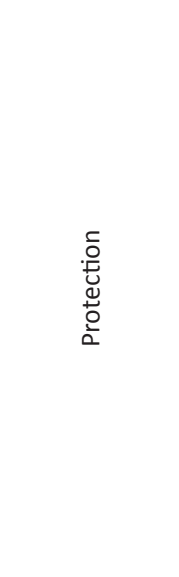 } \\
\hline 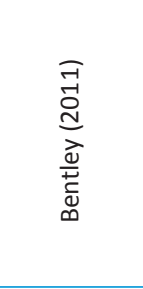 & $\begin{array}{l}\text { - Public space covers all the regions } \\
\text { that are open to the peoples of the } \\
\text { society originally not necessarily } \\
\text { operationally } \\
\text { - Public space is a space that is created } \\
\text { and protected by governmental } \\
\text { officials and are accessible to people }\end{array}$ & $\begin{array}{l}\text { - A key for accessing to a public space } \\
\text { - Governmental perspective for } \\
\text { public assesses } \\
\text { - A key for accessing to an } \\
\text { environmental opportunity }\end{array}$ & $\begin{array}{l}\text { - Social justice, democratic and } \\
\text { meaningful }\end{array}$ & \\
\hline 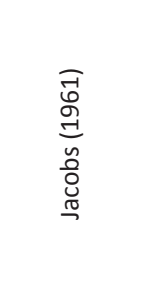 & $\begin{array}{l}\text { - Public space (comprehensive } \\
\text { definition) designed related to all the } \\
\text { sections of the environment such as } \\
\text { public and private, inner and outer, } \\
\text { urban and rural. It Is a space where } \\
\text { people are free like streets, squares } \\
\text { etc. and includes mostly residential, } \\
\text { commercial, and social-civil usage }\end{array}$ & $\begin{array}{l}\text { - A key for social justice in countyand } \\
\text { village } \\
\text { - A key for respecting others' rights } \\
\text { - A key for equity participation } \\
\text { - A key for public access }\end{array}$ & $\begin{array}{l}\text { - Social justice, equity } \\
\text { participation, cooperation and } \\
\text { strengthening people }\end{array}$ & 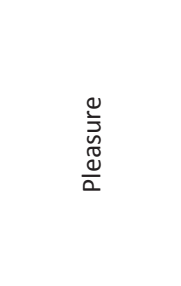 \\
\hline
\end{tabular}

Todays, the villages' important role in economic, social, and political development in regional, local, and international scales and the sequences of being underdeveloped lead to a special attention toward the rural development. So, most researchers believe that rural development's the introduction to the sociopolitical and cultural development concluding in national level developments (Hartel et al. 2014). Rural public spaces should be able to satisfy the spiritual needs and provide people with an acceptable level of quality. 
The rural population public spaces' quantitative needs could be dived into three categories of protection, tranquility, and pleasure. Protection is composed of traffic, security, limitations and unfavorable atmosphere conditions. Tranquility is composed of walking, stopping, sitting, watching, speaking and listening as well as activities and plays. Pleasure, includes visual quality (nature, sunshine, wind, breeze, and plants) which are perceived through senses (Helen 2009).

Therefore, based on what mentioned above, it could be said that the visual and environmental tranquility are the crucial and important components of secured rural environment. For instance, proper color usage in designing the rural furniture is one of the proper solutions in customization of the rural appearance and plays a crucial role in perceiving the environment in a way that the colors are perceived in their best condition by people who are between 16-35 years old (Tveit 2009).The most important function of public spaces in rural tranquility enhancement can be divided into three categories of protector, tranquility and pleasure, which are shown in Figure 2 (Kavvakebi et al. 2012).

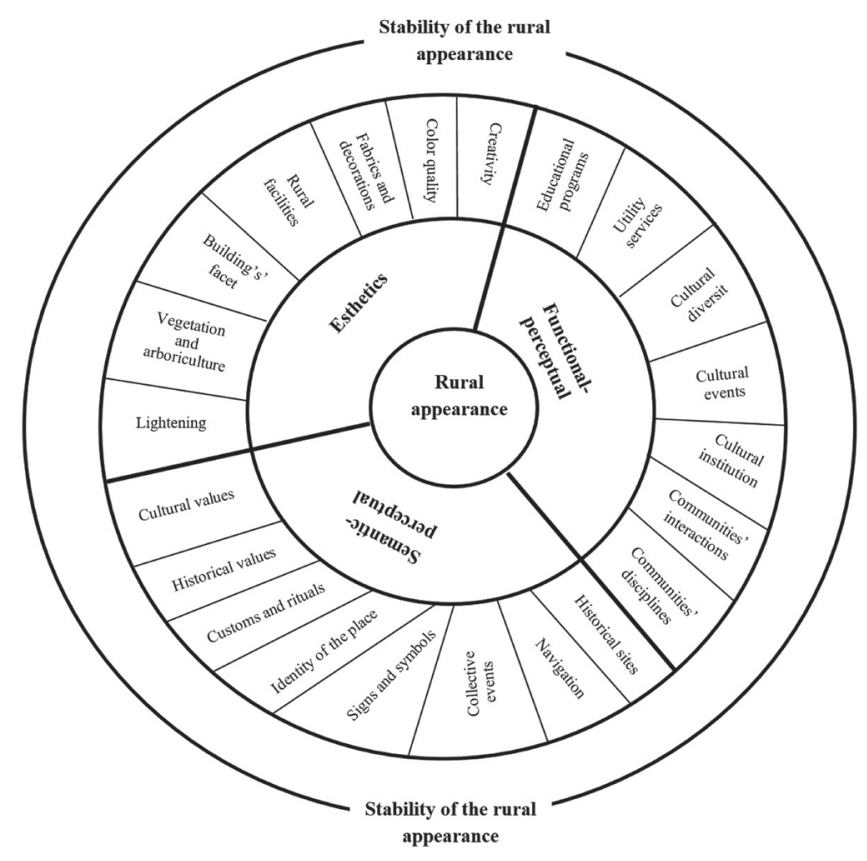

Fig. 2 Public spaces functions in rural regions.

\subsection{Rural population public spaces and Quality life}

Quality life can simply be defined as "the cap county of a phenomenon for survival and growth". In micro level quality life can be defined as the variety of activities in public area and its adaptability with urban and rural spaces in a framework of similar structures of the behavioral state (Idris et al. 2016). The England's architecture and built environment committee head believes that the word "Quality life", meaning quality of life, should replace "livability" when referring to the quality life. Charles Landry also analyzed the meaning of quality life in a different manner by differentiating quality life with an approach consisting of four main topical functions including economic quality life, social quality life, and cultural and environmental quality life and liveliness. Therefore, a vital space is spaces in which people spend large amount of their time not obligatory but voluntary (Tveit 2009). Table 2 shows effective factors on quality life from theoreticians' perspectives.

Continuity of the people's settlement in villages can be the source of economic and cultural civilization of a society. With keeping and protecting the rural landscapes and perspectives of villages and the esthetic quality of their spaces, not only can it be updated with the changes in technology, industrial and economic system, but also can stabilize and strengthen the rural culture and civilization and pave the way for the rural population's quality life and dynamism quality enhancement. Some researchers believe that economic factors such as low level of poverty, job possession, appropriate levels of life

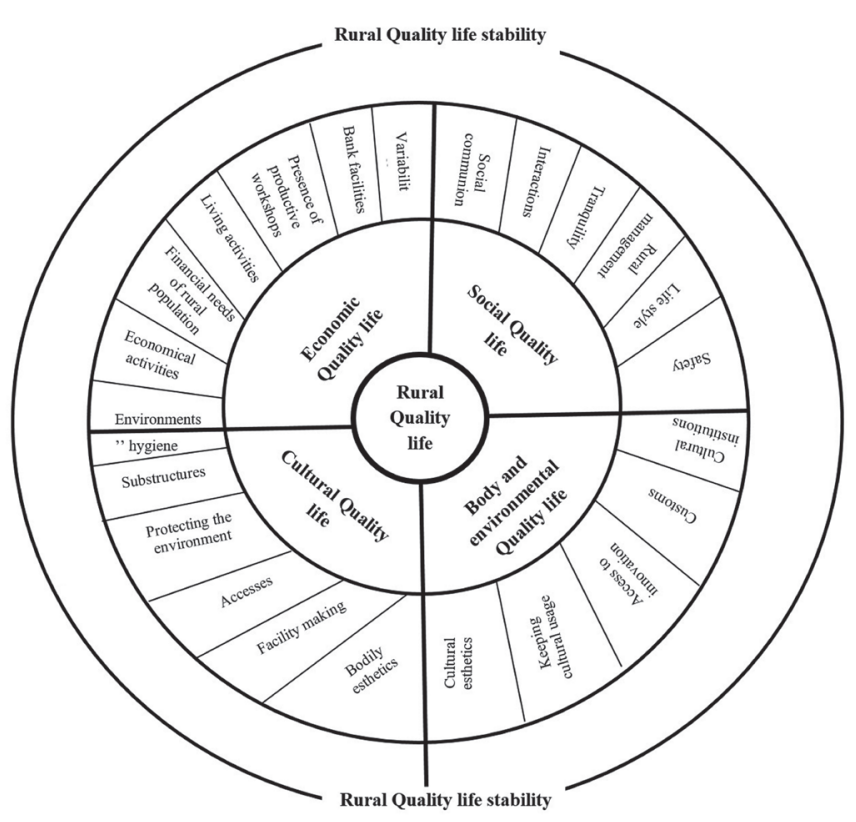

Fig. 3 Functions of public spaces in rural areas.

expenses and income, and access to appropriate credits are indicators of villages quality life. In body dimension, researchers view the quality life indicators as the presence of appropriate substructures locals' desirable access (Whisler et al. 2008), desirable dwelling, appropriate life facilities (Besser et al. 2009), and educational spaces. Figure 3 describes the criterions and indicators of villages' quality life from them the insights were gotten for designing the questionnaire and dependent variables 
Tab. 2 Effective factors on the quality life from theoreticians' perspective.

\begin{tabular}{|c|c|}
\hline Theoreticians & Effective factors Quality life \\
\hline Landry (2000) & $\begin{array}{l}\text { This scholar differentiates Quality life and liveliness: } \\
\text { - Quality life types: economic Quality life, social Quality life, cultural Quality life, environmental quality life } \\
\text { - } 9 \text { necessary criterions for Quality life and liveliness: useful population density, access diversity, safety, identity and } \\
\text { differentiation, creativity, connection and collaboration, organizational capacountyand competition }\end{array}$ \\
\hline $\begin{array}{l}\text { Martin and Brshav } \\
\text { (2005) }\end{array}$ & $\begin{array}{l}\text { This scholar believes that health control includes three main parts: } \\
\text { - attractiveness: trade and exchange, services, residential, arts, culture, entertainment, retailing } \\
\text { - access: deliveries and changes, public transportation, walking and cycling, options for special people with special needs, } \\
\text { personal vehicle } \\
\text { - tranquility: private spaces and privatizing, streets' appearance, feeling of safety in public area, identity and safety } \\
\text { Quality making Quality life: } 1 \text {. Diversity, } 2 \text {. Good public spaces, 3. Purchasing and traveling, 4. Public transportation } \\
\text { Effective functions in Quality life and diversity: } 1 \text {. Decrease in city-dwelling, 2. Activeness, 3. Social change, 4. Leisure and } \\
\text { traveling }\end{array}$ \\
\hline Bentley (2011) & $\begin{array}{l}\text { Quality of furniture and designing: 1. Permeance, 2. Diversity, 3. Readability, 4. Flexibility, 5. Visual adaptability, 6. Richness, } \\
\text { 7. Privatizing ability, 8. Energy consumption productivity, 9. Cleanliness and having the lowest level of air pollution, } \\
\text { 10. Protecting and supporting the nature and wild life (protecting ecosystems) }\end{array}$ \\
\hline Jacobs (1961) & $\begin{array}{l}\text { - Necessity of the combination of main usages (usage diversity) } \\
\text { - Necessity of the short blocks (body diversity) } \\
\text { - Necessity of the buildings with different age and situations (body diversity) } \\
\text { - Sufficient density of population (activity diversity) }\end{array}$ \\
\hline Lynch (2004) & $\begin{array}{l}\text {-1. Survival, } 2 \text {. Safety, } 3 \text {. Adaptability, } 4 \text {. Health providing and genetically diverse creatures, } 5 \text {. Present and future stability of } \\
\text { the biological society Mostly biological and ecological criterions } \\
\text { - Quality life analysis in a large scale }\end{array}$ \\
\hline
\end{tabular}

Source: Authors with available sources, 2016

\section{Method and Instruments}

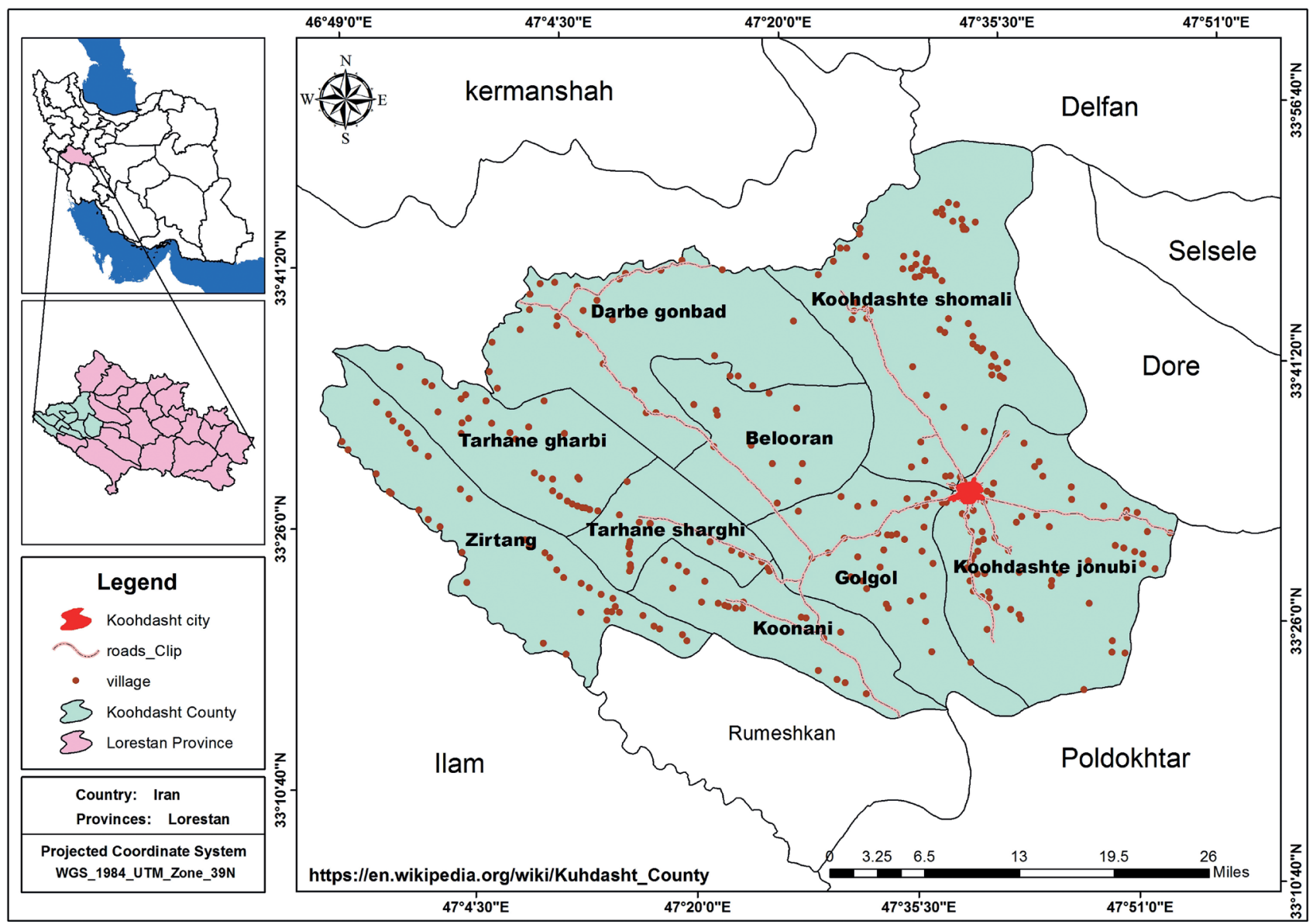

Fig 4 Location of villages in the studied rural area (https://en.wikipedia.org/wiki/Kuhdasht_County). 
Kuhdasht county $\left(33^{\circ} 32^{\prime} \mathrm{N} 47^{\circ} 36^{\prime} \mathrm{E}\right)$, one of the dependencies of Lorestan province, Iran, is connected to Kermanshah from the north, from south and southwest it is connected to Ilam province, and from east it is connected to Khorramabad County. It has the height of 1195 from the sea level. It has a moderate and semi-arid climate with the maximum and minimum temperature of 42 and -7 degrees respectively. It has the average rainfall level of $400 \mathrm{ml}$ annually. Calcareous and Clay constitute the soil type of this region. The samples and signs gathered through the archeology investigations and analysis showed that the climate of the region is part of the Zagros Mountains. Because of having Glaciers, watery valleys, and moderate climate, this region was an appropriate habitat for trees and plants, wild animals, and cave dwellers. This brought about people's effort in culture creation and designing and making rocky tools for satisfying their needs (Figure 4).

Table (3) shows the internal political divisions of Iran and access to services and facilities in the city of Kuhdasht. Political divisions in Iran include (province, county, region, district, city, village) (https:// www.amar.org.ir/english). Also, in Table (3), the existence of services and access to facilities in each village is specified as a percentage (https://www .amar.org.ir/english) also Figure (5), some of the public spaces that people tend to participate in the community is shown.

In the current study, to the purposes mentioned earlier, the research clarified the why and how of the questions and their dimensions. Therefore, the current study is applied in purpose and descriptive analytical in methodology. Two methods were used for data gathering namely documentary method including theoretical studies and the descriptive data for villages' spaces and field study using a five-point Likert-scale questionnaire with the options of very low, low, medium, high, and very high. To analyze the data, SPSS statistical procedures were used. The validity of the questionnaire was calculated using Cronbach's alpha and the results for public spaces' criterions (Esthetics, semantic-perceptual, functional-perceptual), rural quality life dimensions (economic, social, cultural, body, environmental) was 0.749 and 0.767 respectively. After analyzing the gap in the region, effective factors were identified. Firstly, the amount of each indicator constituting public spaces' effective factor share was calculated through the people's perspectives and using Mean as the statistical procedure. For measuring the desirable level, inferential statistics (Regression, Friedman, and Factor Analysis) was used.

The situational zone of the current study is Kouhdasht County, Iran, and it conducted between 20132016 in nine villages whose population is estimated
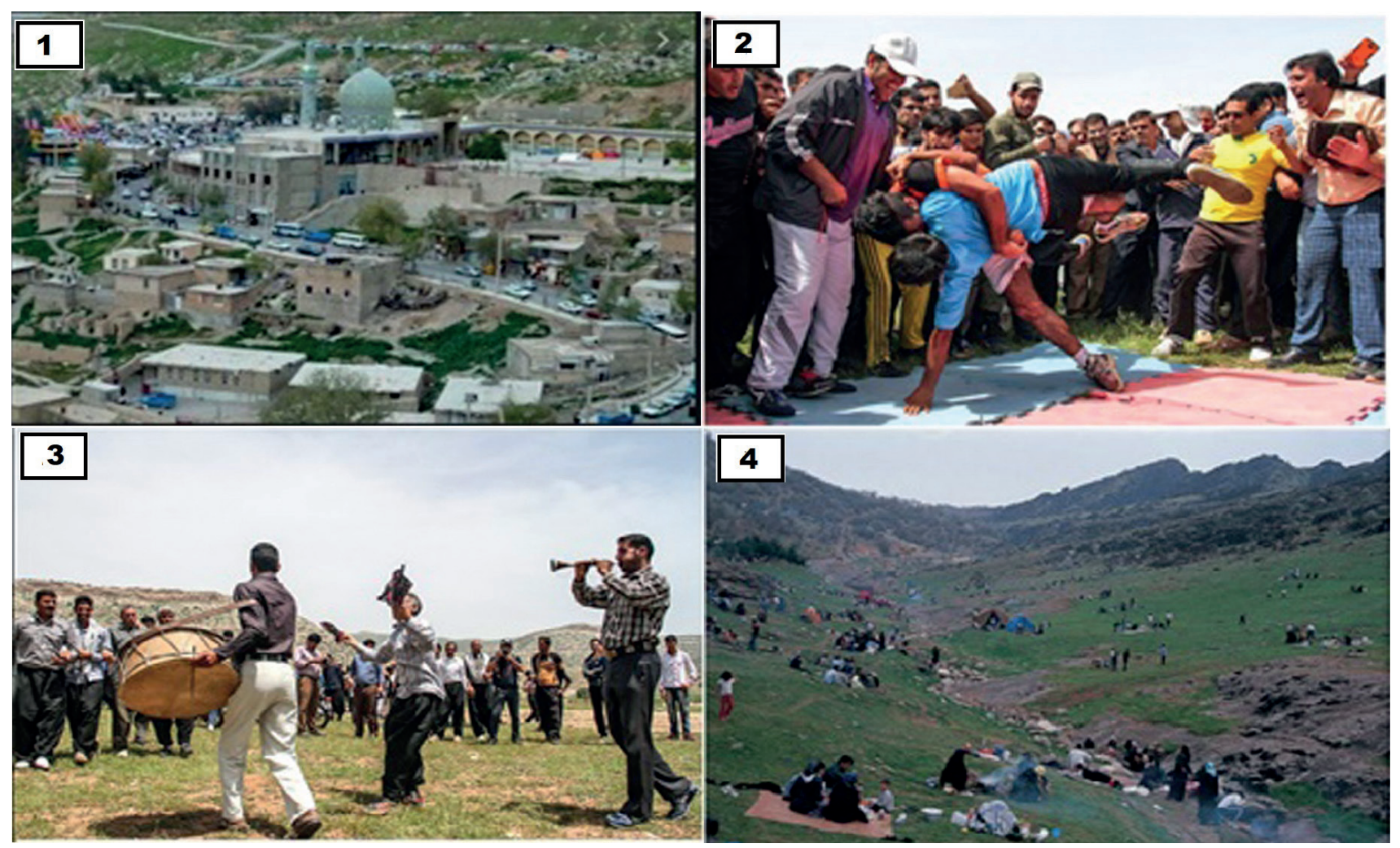

Fig. 5 Studied a sample of public spaces in villages in the county Kuhdasht. 1. Tomb of Imam Zadeh Mohammad in the villages of Darb Gonbad (https://en.wikipedia.org/wiki/Darb-e_Gonbad), 2. Local bazaars Kuhdasht Shomali Rural District (https://en.wikipedia.org/wiki /Kuhdasht-e_Shomali_Rural_District), 3. Local folk dance in the villages of Kuhdasht-e Jonubi Rural District (https://en.wikipedia.org/wiki /Kuhdasht-e_Jonubi_Rural_District), 4. Forest park in Boluran Rural District (https://en.wikipedia.org/wiki/Boluran). 
Tab. 3 Services and access to facilities in the studied district.

\begin{tabular}{|c|c|c|c|c|c|c|c|c|c|c|c|c|}
\hline \multicolumn{5}{|c|}{ Political divisions in Iran } & \multicolumn{8}{|c|}{ Services and access to facilities } \\
\hline $\begin{array}{l}\text { Z्र } \\
\text { हैं }\end{array}$ & 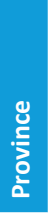 & है & 总 & $\begin{array}{l}\frac{0}{\frac{2}{2}} \\
\frac{\bar{y}}{3} \\
\frac{0}{\circ}\end{array}$ & 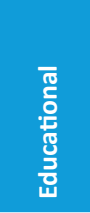 & 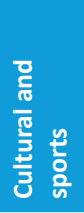 & 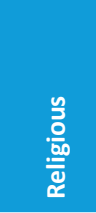 & 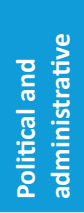 & 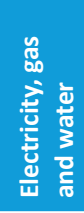 & 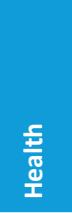 & 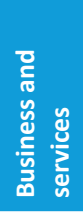 & 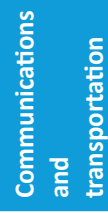 \\
\hline \multirow[t]{9}{*}{ 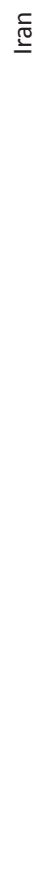 } & \multirow{9}{*}{ 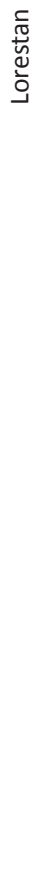 } & \multirow{9}{*}{$\begin{array}{l}\frac{1}{5} \\
\frac{n}{n} \\
\frac{\pi}{0} \\
\frac{5}{3} \\
\frac{1}{2}\end{array}$} & \multirow{2}{*}{$\begin{array}{l}\frac{5}{\pi} \\
\frac{0}{5} \\
10 \\
\frac{10}{0}\end{array}$} & Tarhan Eastern & 12.31 & 0.00 & 121.15 & 24.18 & 40.00 & 7.69 & 12.18 & 16.35 \\
\hline & & & & $\begin{array}{l}\text { Tarhan } \\
\text { Western }\end{array}$ & 9.14 & 0.00 & 101.85 & 19.58 & 70.37 & 7.41 & 10.19 & 9.72 \\
\hline & & & \multirow{3}{*}{$\begin{array}{l}\overline{\frac{\pi}{2}} \\
\stackrel{5}{0} \\
\text { U }\end{array}$} & $\begin{array}{l}\text { Kouhdasht } \\
\text { Jonubi }\end{array}$ & 10.18 & 1.36 & 102.95 & 10.91 & 34.55 & 5.45 & 7.88 & 13.18 \\
\hline & & & & $\begin{array}{l}\text { Kouhdasht } \\
\text { Shomali }\end{array}$ & 5.21 & 0.00 & 96.96 & 3.66 & 60.77 & 0.90 & 4.17 & 3.69 \\
\hline & & & & Koulkoul & 8.89 & 2.08 & 84.38 & 10.12 & 27.08 & 6.00 & 8.33 & 14.32 \\
\hline & & & \multirow{2}{*}{ 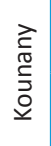 } & Ziyrtang & 6.32 & 0.00 & 96.47 & 6.59 & 27.69 & 2.71 & 4.70 & 5.45 \\
\hline & & & & Kounany & 9.09 & 0.00 & 98.86 & 13.64 & 32.73 & 4.55 & 7.95 & 17.05 \\
\hline & & & \multirow{2}{*}{$\begin{array}{l}0 \\
0 \\
\frac{\pi}{0} \\
\frac{1}{7} \\
0 \\
0 \\
0 \\
\frac{0}{\pi 0} \\
0\end{array}$} & Blouran & 12.94 & 0.00 & 125.00 & 9.24 & 56.47 & 4.84 & 9.80 & 10.29 \\
\hline & & & & Darb Gounbad & 8.07 & 2.63 & 104.61 & 18.05 & 34.74 & 4.33 & 10.09 & 13.82 \\
\hline
\end{tabular}

Tab. 4 population and households in the sample Rural District in research.

\begin{tabular}{|l|c|c|c|c|c|}
\hline \multicolumn{1}{|c|}{ Rural District } & Population & Male & Female & The number of households & Questionnaire \\
\hline Kuhdasht Shomali & 5094 & 2580 & 2514 & 1188 & 22 \\
\hline Kuhdasht Jonubi & 7807 & 3854 & 3953 & 1756 & 34 \\
\hline Koulkoul & 16981 & 8633 & 8348 & 3989 & 74 \\
\hline Tarhan Western & 7287 & 3719 & 3568 & 3033 & 32 \\
\hline Tarhan Eastern & 12704 & 6522 & 6182 & 1376 & 26 \\
\hline Darb Gounbad & 6031 & 3043 & 2988 & 1765 & 31 \\
\hline Kounany & 7160 & 3573 & 3587 & 1094 & 20 \\
\hline Blouran & 4650 & 2395 & 2255 & 1494 & 16026 \\
\hline Ziyrtang & 5821 & 2999 & 2822 & 320 & 25 \\
\hline Total & 73535 & 37318 & 36217 & & 320 \\
\hline
\end{tabular}

Reference: census of the Iranian Statistical Center in 2016

about 73535. Cochran's sample size formula was used for sampling and 320 samples were analyzed. Simple random sampling was used for the questionnaire in nine villages. Table 4 describes the population, families, and number of samples in each village.

$$
n=\frac{\frac{(1.96)^{2}(0.50)(0.50)}{(0.05)^{2}}}{1+\frac{1}{73535}\left(\frac{(1.96)^{2}(0.50)(0.50)}{(0.05)^{2}}-1\right)}=32
$$

$N($ population $)=73535$

$P($ people with characteristic $)=50 \%$
$Q$ (people lack characteristic $)=50 \%$

$D$ (speech correctness difference probability) $=5 \%$

$T($ speech correctness rate $)=50 \%$

\subsection{Regression Model}

The main purpose of the regression is to find an approximate relationship between independent and dependent variable. Linear regression used when there is a linear relationship between two variables; otherwise, non-linear regression will be used. Hence, if we name the dependent variable (Y) and the 
independent variable $(\mathrm{X})$, the simple linear regression model of $(\mathrm{Y})$ based on $(\mathrm{X})$ is:

$$
y=a+B X
$$

In the above formula, and $\mathrm{b}$ are fixed numbers and coefficients of is the intercepts, which shows the amount of $Y$ for, and $b$ is the slope of the regression line. 1 unit increase in $Y$ will show an increase in $X$. $\mathrm{a}$ and $\mathrm{b}$ parameters' values are passive and should be calculated through the information and observation of $(x, y)$. Actually, there is no precise linear relationship between $x$ and $y$ variables. In other words, $(x, y)$ cannot be placed on a straight line, but these points are deviated from the straight line.

It can be written for the deviation of the $i^{\text {th }}$ observation with $e_{\mathrm{i}}$ :

$$
y_{i}=y+e_{i}
$$

In which, $y_{i}$ is the intercept of $i^{\text {th }}$ observation and $\hat{y}_{i}=a+b x_{i}$ is the intercept of regression line for $x_{i}$. To put it in another words, the best fitting is reached through minimizing the sum of the error squares $\sum e_{i}{ }^{2}$, which is calculated through this formula:

$$
\begin{gathered}
f(a, b)=\sum_{i-}^{n} e_{e^{2}}=\sum_{i=1}^{n}\left(y_{i}+y_{i}\right)^{2}=\sum_{i=1}^{n}\left(y_{i}-\left(a+b x_{i}\right)\right)^{2} \\
\frac{d f(a, b)}{d f}=\sum_{i=1}^{n}-2\left(y_{i}-\left(a+b x_{i}\right)\right) \\
\frac{d f(a, b)}{d f}=\sum_{i=1}^{n}-2 x_{i}\left(y_{i}-\left(a+b x_{i}\right)\right)
\end{gathered}
$$

Normal equations found through above formula:

$$
\sum_{i=1}^{n} x_{i y i}=a \sum_{i=1}^{n} x_{i}+B \sum_{i=1}^{n} x_{i} x_{1^{2}}
$$

$\mathrm{a}$ and $\mathrm{b}$ can be found by solving the normal equations:

$$
\begin{gathered}
a=\bar{y}-B \bar{x} \\
F_{j}=\sum w_{j i} x_{i}=w_{j 1} x_{1}+w_{j 1} x_{1}+w_{j 2} x_{2}+\cdots+w_{i p} x_{p}
\end{gathered}
$$

For the meaningfulness of the regression slope the below formula is used:

$$
t=\frac{b}{\sqrt{\frac{M S E}{S_{X X}}}}
$$

In this formula, MSE (mean of sum of errors) and $S_{X X}$ are calculated through using below formula:

$$
S_{X X}=\sum\left(X_{1}-X\right)^{2}
$$

\subsection{Friedman Test}

The Friedman Test divided in a two-way table consisting of $\mathrm{N}$ rows and $\mathrm{K}$ columns. The rows include subjects or sample set of subjects and the columns include different situations. If the subjects' marks, which are a specific situation, be the focus of the study, each row signifies the mark of one subject in $\mathrm{k}$ situation. The database of the very test is an ordinal one. The marks will be ranked in different rows meaning that when the $\mathrm{k}$ situation is being observed, the marks will be arranged from 1 to k. Friedman test shows the probability that the columns of the table (sample groups) come from the same population. When the number of rows and columns are not too small, it can be shown that they have equal distribution to 'chi-square' and degrees of freedom of $\mathrm{df}=\mathrm{k}-1$ and the calculation procedure is:

$$
X_{r}^{2}=\frac{12}{N K(K+1)} \sum R_{j}^{2}-3 N(k-1)
$$

$N=$ number of rows

$K=$ number of columns

$R_{I}^{2}=$ determining the significancy of $X_{r}^{2}$ using

\subsection{Factor Analysis}

Factor analysis is a technique used to describe variability among observed correlated variables in terms of lower number of unobserved variables. Being economical is the main purpose of factor analysis by using the smallest clarifying concepts for maximum level of common variance in correlation matrix. The main hypothesis of the factor analysis is that the underlying factors of the variables can be used in clarifying sophisticated phenomena and the observed correlation between variables signifies their association in these factors. The purpose of factor analysis is identifying the unobserved variables based on a set of observed variables. Factor, is a new variable calculated through linear combination of the observed variables main marks using this formula:

$$
F J=X_{i} W_{i j}+x_{2} w_{2}+\cdots+x_{p}^{w} F_{j}=\sum w_{j i} x_{i}=w_{i 1} x_{1}+w_{j 2} x_{2}+\cdots+w_{j p} x_{p}
$$

In this formula, $w$ represents factor score coefficients and $p$ is the number of variables. These factors are hypothetical and theoretical structures in themselves playing a vital role in helping to interpretation of the consistency in dataset. Therefore, factor analysis is valuable in that it provides the researcher with a useful organizational pattern that can be used for interpretation of copious behaviors with the maximum level of saving in clarifier factors.

Table 5 shows the descriptive statistics for the participants. It can be inferred from the table that considering age, participants who are between $21-30$ years 
old with the frequency of 178 and 54.3 percent have the highest numbers of answers. On the other hand, considering the educational level, associate degree and higher choice with the frequency of 110 and 34.4 percent have the highest number, and considering the gender, 170 participants with the level of 52.3 and considering the job, the housewife choice with the frequency of 122 and level of 41.5 have the highest number of answers.

Tab. 5 Descriptive information of local people's respondents.

\begin{tabular}{|c|c|c|c|}
\hline \multicolumn{4}{|c|}{ Local people } \\
\hline Variable & Ccategory & Frequency & Percentage \% \\
\hline \multirow{2}{*}{ Gender } & Female & 150 & 47.7 \\
\hline & Male & 170 & 52.3 \\
\hline \multirow{4}{*}{ Age } & 20-30 years & 178 & 54.3 \\
\hline & $31-40$ years & 75 & 25.6 \\
\hline & $41-50$ years & 37 & 10.5 \\
\hline & 51 years and above & 30 & 9.6 \\
\hline \multirow{6}{*}{ Education } & illiterate & 35 & 8.7 \\
\hline & Been reading and writing & 20 & 6.2 \\
\hline & Primary & 25 & 6.6 \\
\hline & Guidance & 38 & 12 \\
\hline & High school & 92 & 32.1 \\
\hline & Graduate And higher & 110 & 34.4 \\
\hline \multirow{6}{*}{ Job } & Government employees & 35 & 10.9 \\
\hline & Agriculture & 61 & 18.2 \\
\hline & Self-employed & 88 & 26.4 \\
\hline & Retired & 9 & 1.9 \\
\hline & housewife & 122 & 41.5 \\
\hline & Other & 5 & 1.1 \\
\hline
\end{tabular}

\section{Analysis of Results}

In the current study, for identifying and analyzing the role of public spaces effective indicators, three criterions namely esthetic, semantic-perceptual, and activity-based functional were used. Each criterion includes components and variables. Variance analysis was used for analyzing the variables and the results showed that the variables of the presence of utility services, social interactions in situations, and the presence of educational programs with the variances of 1.258, 1.240, and 1.205 have the highest rates from people's perspectives towards the issue respectively. That it can be researched (Song et al. 2016) compared. They in this research with purpose attempt to examine how privately owned public spaces through incentive zoning have played out as a means to generate public spaces New York City, And the results were Using spatial statistical analyses, we find that the inclusion of privately owned public spaces reduces overall average distance to the nearest public space from both working and living population (Figure 6).

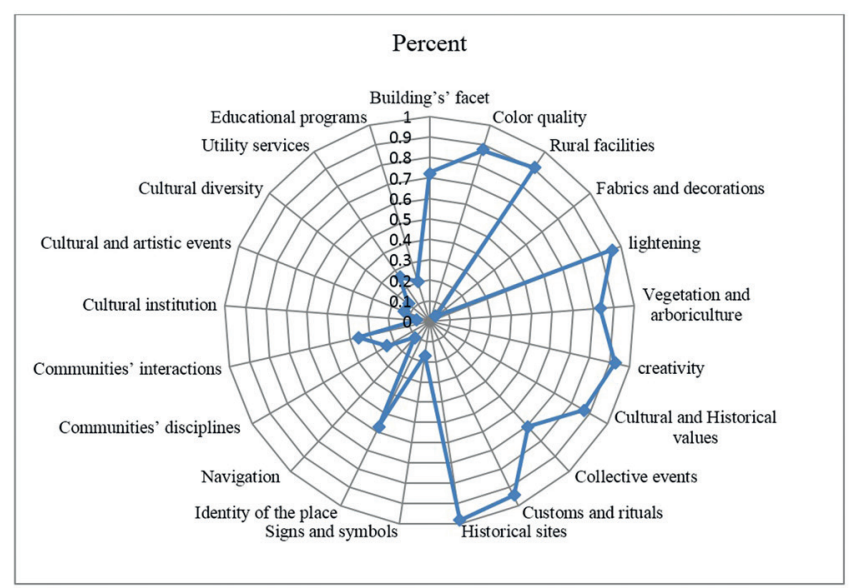

Fig. 6 The effects of the components of public spaces on the development of the quality of viability and dynamics of villagers.

Figure 7 shows the variables and rural public spaces indicators Mean in the current study in a way that the esthetic indicator, semantic-perceptual indicator, and functional-perceptual indicator have the Mean of $4.03,3.61$, and 3.99 respectively. Hence, in esthetic indicator, building façade variable $(\mathrm{M}=4.30)$, in functional-perceptual indicator, the utility service variable $(\mathrm{M}=4.25)$, and in semantic-perceptual indicator, the historic sites variable $(M=3.89)$ has the highest percentages of Mean.

Inferential statistics was used for analyzing the descriptive statistic of the participants, which

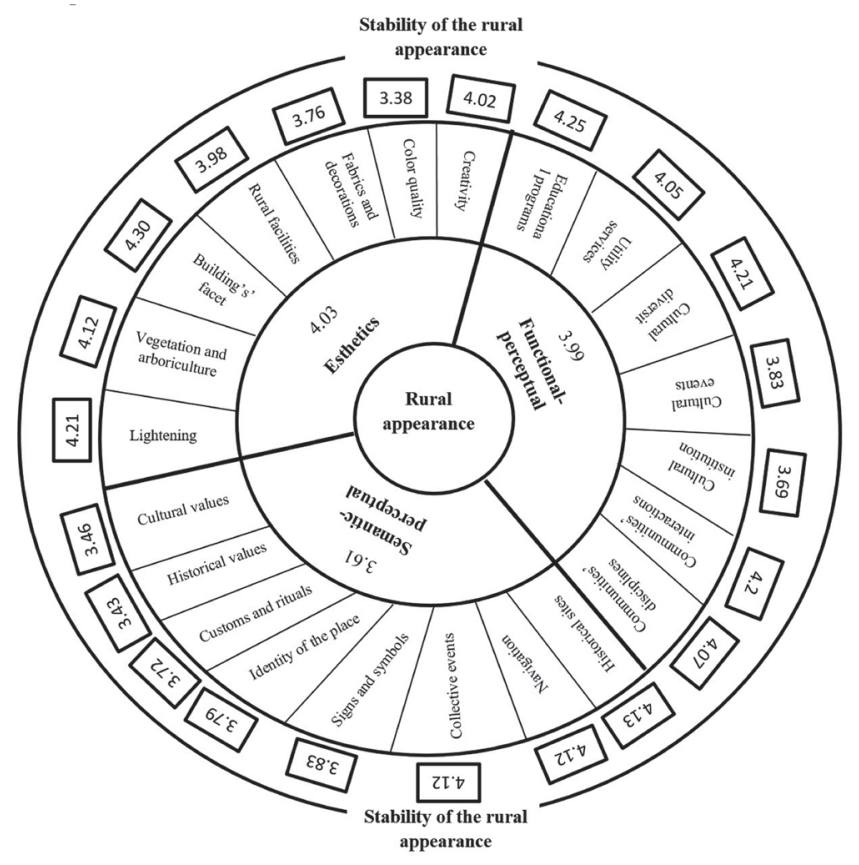

Fig. 7 Average indices and variables a rural landscape used by local people's views. 
referred to in research method section, and answering the research questions. Table 6 shows that ranked Friedman test was used for analyzing the significant difference among these branches. Based on this test, there is a significant difference among esthetic, semantic-perceptual, and activity-based -functional criterions at alpha level of 0.01 . ordinal mean analysis of the data resulted from the quantitative analysis of the available capacities in enhancing the rural regions quality life and dynamism quality signifies the crucial role played by public spaces effective factors in quality life enhancement to a higher level above medium one. Therefore, regarding the results of the Friedman test it can be inferred that the reasons for the vital role of the public spaces effective factors in rural regions quality life and dynamism quality from local people's perspectives.

1) The esthetic variable group stands first in the focused villages of the study with the mean rate of 2.89 from local people's perspectives which was higher than desirable rate, because of the building facets (material, color, window form), color quality, rural facilities (bus station, bench, dustbin), walls fabrics and decoration, lightening, vegetation and environment attractiveness, and creativity. This study can be compared with (Kline 2006) study believing that social and economic changes of the rural outdoor spaces together with population growth, income increase, and interest and enthusiasm increase pave the way for supporting the protection of the outdoor spaces and unprotected lands.

2) Semantic-perceptual variables group stands second in the triple factors with the mean of 1.80 because of the historical and cultural values, individual and collective events, customs and traditions, historical sites, signs and symbols, places' identity, and navigation sense. Our information base did not provide us with any report for drawing a comparison.

3) Activity-based -functional variables group have the lowest ordinal mean from the local people's perspectives because of the social and natural supervision on the space, social interactions, presence of cultural institutions, artistic and cultural events, presence of utility services and educational programs. The results can be compared with (Jalaladdini and Oktay, 2012) study in Cyprus believing that the public spaces functions in social, walking, and tourism value aspect play a vital role in pleasure and dynamism.

Factor analysis was used for analyzing the accuracy of the study and reducing the number of variables into smaller and crucial ones in determination of each public space criterion's share in rural regions as well as identifying the most important factors in increasing the quality life. 20 factors were extracted by comprehensive analysis of the theoretical studies and fieldwork in the focused zone of the study. KMO indicator and Bartlett's test were also used for analyzing the internal consistency and suitability of the data for factor analysis. The result of the Bartlett's test was significant in $99 \%$ confidence interval and suitable KMO index (Table 7) signifies the internal consistency and suitability of the data for factor analysis.

Tab. 6 Significance of the mean difference of sample criteria based on Friedman test statistic.

\begin{tabular}{|l|c|c|c|}
\hline \multicolumn{1}{|c|}{ Local people's views } \\
\hline Criteria & Number & $\begin{array}{c}\text { Mean } \\
\text { Numerical }\end{array}$ & $\begin{array}{c}\text { Average } \\
\text { Ranking } \\
\text { Friedman's }\end{array}$ \\
\hline Esthetics & 320 & 14.4 & 2.89 \\
\hline Semantic-perceptual & 320 & 3.69 & 1.80 \\
\hline Functional-perceptual & 320 & 3.58 & .89 \\
\hline Chi-Square & \multicolumn{3}{|c|}{18.86} \\
\hline df & \multicolumn{3}{|c|}{0.000} \\
\hline Asymp. Sig. & \\
\hline
\end{tabular}

Tab. 7 Bartlett test at a meaningful level.

\begin{tabular}{|l|l|c|c|c|}
\hline Total analyzed & Opinions & $\begin{array}{c}\text { Kaiser- } \\
\text { Meyer-Olkin } \\
\text { Measure of } \\
\text { Sampling } \\
\text { Adequacy. }\end{array}$ & Bartlett's Test & Sig. \\
\hline $\begin{array}{l}\text { Total indices of } \\
\text { public spaces } \\
\text { in improving } \\
\text { the quality of } \\
\text { viability and } \\
\text { dynamism of } \\
\text { villagers }\end{array}$ & $\begin{array}{l}\text { Local } \\
\text { people }\end{array}$ & .850 & 913.34 & 0.000 \\
\hline
\end{tabular}

Tab. 8 Extracted factors with special value, percentage of variance and cumulative percentage of variance.

\begin{tabular}{|c|l|c|c|c|}
\multicolumn{4}{|c|}{ People's View } \\
\hline \multirow{2}{*}{ Row } & \multirow{2}{*}{ Factor } & \multicolumn{3}{|c|}{ Rotation Sums of Squared Loadings } \\
\cline { 3 - 5 } & & Total & $\%$ of Variance & $\%$ of Cumulative \\
\hline 1 & factor one & 2.28 & 11.30 & 11.30 \\
\hline 2 & factor two & 2.06 & 10.28 & 21.58 \\
\hline 3 & factor three & 1.93 & 9.73 & 31.32 \\
\hline 4 & factor four & 1.53 & 7.70 & 39.03 \\
\hline 5 & factor five & 1.47 & 7.33 & 46.37 \\
\hline 6 & factor six & 1.31 & 6.59 & 52.96 \\
\hline
\end{tabular}

Considering the effective factors, 6 factors were extracted with Eigenvalues exceeding 1 for the rural public spaces. Table 8 describes the number of extracted factors with their Eigenvalues, their variance percentages, and cumulative frequency of variance percentages. Eigenvalue shows each factor's share from the total variances and the bigger the Eigenvalue the more important and effective is the factor. The first factor has the highest and the last factor has the 
lowest role in explaining the variables and the sex factors explained $52.640 \%$ of the total variances.

\subsection{Factor one: perceptual vision}

Based on Table 9, historical sites, sign and symbols, navigation senses, color quality, rural environments attractiveness variables stand for the first factor. Factor loadings show that these variables have high positive correlation with the first factor. The eigenvalue of this factor is 2.28 exceeding other factors and explains 11.301 percent of the total variance. So, it can be inferred that there is a high correlation between the variables underlying the perceptual vision variable and they have a conspicuous effect on the rural population's quality life. The even findings can be with results (Nasution et al. 2014), In medan, Indonesia compare and concluded the research found that the public open space in medan county is a livable place when it has a high level of usage. The livable public open space relates to quality of life via the satisfaction with health, recreation and urban environment.

Tab. 9 Variables of each factor and factor loadings resulted from rotated matrix.

\begin{tabular}{|c|c|c|}
\hline Factors & Variables & Factor loadings \\
\hline \multirow{5}{*}{$\begin{array}{l}\text { Perceptual } \\
\text { vision }\end{array}$} & Historical memos and sites & 0.768 \\
\hline & Signs and symbols & 0.542 \\
\hline & Navigation sense & 0.658 \\
\hline & Color quality & 0.568 \\
\hline & Environmental attractiveness & 0.615 \\
\hline \multirow{4}{*}{$\begin{array}{l}\text { Main body } \\
\text { of the buildings }\end{array}$} & $\begin{array}{l}\text { Building facets (materials, colors, } \\
\text { windows form) }\end{array}$ & 0.501 \\
\hline & Walls' fabrics and decorations & 0.647 \\
\hline & Passages lightening & 0.651 \\
\hline & Accessibility of the passages & 0.575 \\
\hline \multirow{4}{*}{$\begin{array}{l}\text { Culture and } \\
\text { communities }\end{array}$} & Cultural and artistic events & 0.506 \\
\hline & Presence of cultural institutions & 0.563 \\
\hline & Cultural and historical values & 0.737 \\
\hline & Customs and rituals & 0.580 \\
\hline \multirow{3}{*}{ Activities } & Presence of educational program & 0.699 \\
\hline & Peoples' creativity in activities & 0.625 \\
\hline & Presence of utility services & 0.553 \\
\hline \multirow{2}{*}{ Environmental } & Vegetation and arboriculture & 0.621 \\
\hline & Climate elements & 0.586 \\
\hline \multirow{3}{*}{$\begin{array}{l}\text { Social } \\
\text { interaction }\end{array}$} & Collective and individual events & 0.774 \\
\hline & $\begin{array}{l}\text { Social and natural supervision } \\
\text { of the space }\end{array}$ & 0.648 \\
\hline & Social interactions in places & 0.568 \\
\hline
\end{tabular}

\subsection{Factor two: buildings' skeleton}

The variables underlying this factor are building facets (materials, color, window forms), walls' fabrics and decoration, passages lightening and associability. The factor loading of these variables is between 0.501 and 0.651 and all of them are positively correlated with the second factor. Considering the importance of the constituting variables with eigenvalue of 2.06 , they explain 10.286 percent of the total variance. in the same Relation (Kurz 2014), In his research in bane to this conclusion Receipt the analyses show that public spaces could play an important role in creating, respectively reshaping towns and villages and improve the quality of the site.

\subsection{Factor three: culture and communities}

This factor includes variables such as cultural and artistic events, presence of cultural institutions, historical and cultural values, rituals, and customs. This factor's eigenvalue in 1.93 and it explains 9.739 percent of the total variance. There is also a high correlation among all the variables. The findings can be with results (Kaźmierczak 2013; Francis et al. 2012) compared and they believe public spaces also provide opportunities for social interactions that contribute to creating sense of community and neighborhood social ties.

\subsection{Factor four: activities}

Variables such as the presence of educational programs, people's creativity in activities, and activity in utility services constitute the fourth factor with eigenvalue of 1.53 explaining 7.707 percent of total variances. It can be inferred from these variables that activities play a crucial role in rural population's quality life enhancement. The variables of this factor are correlated with each other with factor loadings between 0.533 and 0.699 research (Yoon and Srinivasan 2015), at of the Pearl River Delta in China cited and concluded the public spaces in towns, public facilities to increase the quality of life provided and paves the way for increased recreational facilities, Availability of public spaces for activities created and where people are satisfied.

\subsection{Factor five and six: social interaction and environment}

Factors five and sic with two and three variables and eigenvalues of 1.47 and 1.31 explained 7.338 and 6.591 percent of the total variances respectively. Factor five variables are vegetation and arboriculture, and local spaces and factor six variables are individual and collective events, natural and social supervision considering all the social interactions for this factor. In this area can be researched (Ismail and Said 2015), in Malaysian cities there have been mentioned and concluded this paper argues that community participation in the design and planning of urban public spaces can draw residents to establish 
a sense of attachment that may lead to community maintaining the spaces. Also (Friedmann 2007), in his research with title "Reflections on Place and Place-making in the Cities of China" with purpose this article is about the small spaces of the county we call 'places'. Places are shaped by being lived in; they are spaces of encounter where the little histories of the county are played on. Concluded, place-making in today's China is a contested process. The county is filling up with immense, architect-designed, nonplace spaces, from airports and subways to luxury hotels, office towers and suburban malls.

General Linear Model has been used for investigating the public spaces effective factor roles and consequences on quality life and dynamism quality. Therefore, for the investigation of local people's perspective: esthetic, functional perceptual, and activity-based - functional variables are used as independent variables and from quality life criterions: economic, social, cultural, and environmental variables are used as dependent ones in general linear model. ${ }^{1}$ Fitting growth regression model signified the positive effects of public spaces effective factors in rural population's quality life and dynamism quality enhancement at the level of 0.723 (Table 10).

Tab. 10 Analysis of variance of factors affecting the quality life of villagers on the role of effective factors in public spaces.

\begin{tabular}{|c|c|c|c|c|}
\hline Model & $\mathbf{R}$ & $\mathbf{R}$ Square & $\begin{array}{c}\text { Adjusted } \mathbf{R} \\
\text { Square }\end{array}$ & $\begin{array}{c}\text { Std. Error of the } \\
\text { Estimate }\end{array}$ \\
\hline 1 & 0.723 & 0.523 & 0.515 & 0.322 \\
\hline
\end{tabular}

In the current study, the effective indicators and factors roles in the focuses villages' dynamism quality were specified by general linear model synchronously. The results showed that all the fourfold indicators which are economic, social, cultural, body and environmental are significant (Table 11).

Tab. 11 Analysis of variance based on the existence of a linear relationship between the degree of satisfaction of the people and the effective factors of the general spatial criteria.

\begin{tabular}{|l|c|r|r|r|r|} 
Components & Sum of squares & df & $\begin{array}{c}\text { Mean } \\
\text { Square }\end{array}$ & F & Sig. \\
\cline { 1 - 4 } Regression & 14.94 & 4 & 3.373 & & \\
\cline { 1 - 4 } Residual & 13.65 & 316 & 0.054 & 69.26 & 0.000 \\
\hline Total & 28.59 & 320 & & & \\
\hline
\end{tabular}

1 Regression $y=a+b x$ was used for the analysis of the public space's effective indicators roles in rural population's quality life and dynamism which shows a significant level for the used indicators.
Table 12 indicates that by analyzing $ß$ values it can be inferred that from among the fourfold indicators, body and environmental indicators $(0.424)$ are the most effective and cultural indicators $(0.028)$ are the least effective ones in quality life in the focused villages of the study.

Tab. 12 The coefficients of the intensity of relations between variables of public spaces on the Quality life of villagers.

\begin{tabular}{|c|c|c|c|c|c|}
\hline \multirow{3}{*}{ Name variable } & \multicolumn{5}{|c|}{ Coefficients } \\
\hline & \multicolumn{2}{|c|}{$\begin{array}{l}\text { Unstandardized } \\
\text { Coefficients }\end{array}$} & \multirow{2}{*}{$\begin{array}{c}\begin{array}{c}\text { Standardized } \\
\text { Coefficients }\end{array} \\
\text { Beta }\end{array}$} & \multirow[t]{2}{*}{$\mathbf{T}$} & \multirow[t]{2}{*}{ Sig. } \\
\hline & B & Std. Error & & & \\
\hline (Constant) & 1.66 & 0.14 & - & 11.550 & 0.000 \\
\hline Cultural & 0.019 & 0.033 & 0.028 & 0.575 & 0.066 \\
\hline social & 0.235 & 0.034 & 0.363 & 6.902 & 0.000 \\
\hline Economic & 0.063 & 0.035 & 0.102 & 1.789 & 0.006 \\
\hline $\begin{array}{l}\text { Environmental } \\
\text { and physical }\end{array}$ & 0.245 & 0.032 & 0.424 & 8.277 & 0.000 \\
\hline
\end{tabular}

Figure 8 shows variable means and quality life indicators in the focused zone of the study in which local people's expectations are investigated in relation to the quality life level. From among the considered indicators, economic quality life indicator, social quality life indicator, cultural quality life indicator, and body and environmental indicator have the means of $3.67,3.72,3.60$ and 3.91 respectively. This suggests that attention towards the quality life in the focused villages is of paramount importance and local managers and authorities should pave the way for the

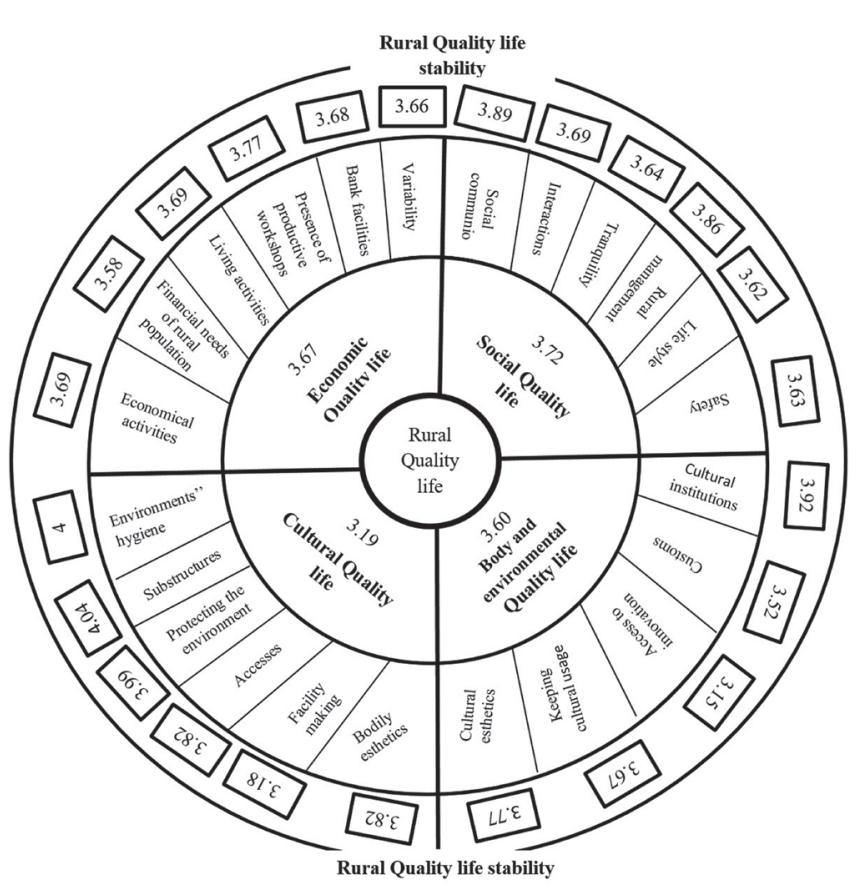

Fig. 8 Average indices and quality of life used by local people's views 
enhancement of public spaces in urban and rural regions. In the same line, (Bolívar et al. 2010), study can be referred to which believes that body safety and interaction between body and space should be taken into account in public spaces designing (Figure 8).

\section{Discussion}

In rural planning today, the attention of public spaces such as streets, squares and communication nodes have a valuable place in the quality of life of local people, this is due to the effects of these spaces on the cultural and social aspects of the villagers. Due to their special nature and function, rural public spaces play an effective role in the spatial and physical structure of villagers and the semantic and mental reproduction of local people. So, the social value of rural public spaces makes them significant within the rural, since they are involved with people needs, from the very basic to the complex. As such, public spaces affect local people's quality of life. They have to afford local people various activities; otherwise, parts of the society will be pushed out of the public realm which results in serious limitations for the daily lives of local people. In addition, The Attention to the function of public spaces should be considered as one of the guidance in the implementation of rural local plan. The content of the plan is very important as an evidence of the community representation to fulfil their right in the local plan.

Attention to social value (quality life) has been increased in the recent rural planning theories owing to the negative effects of the visual-artistic trends in the rural design and due to focus on the requirements of Machine life rather than pedestrian needs. In this context, reviewing various approaches and aspects in rural public space was found important to reveal the interrelationship between the physical environment and the social environment. The key issues concerning quality life in a place are the presence of people at different times and the compatibility of public spaces diverse activities. quality life relates to various dimensions of a public space including both physical and social aspects. In rural planning, no attention is paid to public spaces, have the potential to be transformed into vibrant and quality life public spaces by hosting various activities and events. The analysis of the public spaces in Kuhdasht County and the most quality life and dynamism quality.

Spaces in these counties, shows how they work socially. In county, the presence of people is evident at different times. However, the determinants of quality life in applied spaces such as natural landscapes, mosques, markets, rural public squares are different. County views and historical and cultural fields is vital owing to the presence of the visitors and tourists are the main users that make the area vibrant. It can be concluded that not all public spaces have same reasons or work in a similar way. Hence, a place could be considered quality life with different basis which eventuate to different feelings in the space. Whether two spaces have similar or different basis and reasons for dynamism quality, it is obvious that quality life spaces are healthier and safer where people could interact more and tend to stay longer since they enjoy their time in public. This presence also attracts other people's attention, and it makes a cycle. If a place is attractive, the people would come and if people are present, the place would become even more attractive. However, it should be ensured that the presence of people is not possible through the commercialized functions only, but supported by pleasant pedestrian corners/facilities enabling them to sit and spend the time without necessarily eating or drinking. Therefore, in order to answer the first question, the findings showed that the perceptual image factor with a value of variance (11.301) percent, the body factor of buildings with 10.286 percent variance, culture and communities' factor with a value of 9.739 percent Variance, activity factor with $7.707 \%$ variance and environmental factor and social interactions each explained 7.338 and $6.591 \%$ of total variance. This shows that the first factor had the most and the sixth factor had the least effects. Also, in order to answer the second question, the findings of multivariate regression have shown that its fit is 0.723 , which shows the positive effects of the components of public spaces in improving the quality of life of villagers. Expressive values showed that environmental and physical indicators had the most and cultural indicators had the least effects.

\section{Conclusion}

The results of the study showed that from among the considered criterions, esthetic, semantic-perceptual, and activity-based -functional with the rates of 2.52, 1.79 and 0.69 have the highest rank and effect on the life quality indicator. On the other hand, the results of the factor analysis showed that the first factor, visual perception, has the highest and the sixth factor, social interaction, has the lowest part in explaining the total variables and from local people's perspectives the 6 factors collectively explained 52.640 percent of the total variables. The fitting growth regression model indicated the positive significant effect of public spaces effective factors on rural population's quality life and dynamism quality enhancement was 0.723 , which shows a significant relationship between public spaces indicators roles in rural population's quality life and dynamism quality enhancement in the focused zone of the study.

Now, according to we must underline and hear the borderless voices (the Local people). Then, we need a written proof upon the space for legality rural plan for the local community to resolve the issues. When the physical aspects of space can accommodate the 
space needs of the Forgotten, accommodative public space in Local people quality life will be created. Thus, as society will be educated to learn and share, to respect the rights of other users in the rural, and consequently the physical quality of the visual rural will be better because there are no annexation of space and overlapping activities. So, we can create the public space for Local People in line with the quality-of-life use.

\section{Acknowledgements}

Thank the cooperation of local people and government agencies in the city of Kuhdasht who helped us in the process of facilitating the investigation.

\section{References}

Beck, H. (2009): Linking the quality of public spaces to quality of life. Journal of Place Management and Development 2(3), 240-248, https://doi .org/10.1108/17538330911013933.

Bolívar, J., Daponte, A., Rodríguez, M., Sánchez, J. J. (2010): The influence of individual, social and physical environment factors on physical activity in the adult population in Andalusia, Spain. International Journal of Environmental Research and Public Health 7(1), 60-77, https://doi.org/10.3390/ijerph7010060.

Besser, T. L., Recker, N., Parker, M. (2009): The impact of new employers from the outside, the growth of local capitalism, and new amenities on the social and economic welfare of small towns. Economic Development Quarterly 23(4), 306-316, https://doi .org/10.1177/0891242409340899.

Carmona, M., Heath, T., Tiesdell, S., Oc, T. (2004): Public Places Urban Spaces. Routledge.

Francis, J., Giles-Corti, B., Wood, L., Knuiman, M. (2012): Creating sense of community: The role of public space. Journal of Environmental Psychology 32(4), 401-409, http://dx.doi.org/10.1016/j.jenvp.2012.07.002.

Friedmann, J. (2007): Reflections on place and placemaking in the cities of China. International Journal of Urban and Regional Research 31(2), 257-279. https:// doi.org/10.1111/j.1468-2427.2007.00726.x.

Gehl, J., Gemzøe, L. (1999): Public Spaces Public Life Copenhagen 1996. Copenhagen.

Hartel, T., Fischer, J., Câmpeanu, C., Milcu, A. I., Hanspach, J., Fazey, I. (2014): The importance of ecosystem services for rural inhabitants in a changing cultural landscape in Romania. Ecology and Society 19(2), 42-49, https://doi .org/10.5751/ES-06333-190242.

Helen, B. (2009): Linking the quality of public spaces to quality of life. Journal of Place Management and Development 2(3), 240-248, https://doi .org/10.1108/17538330911013933.

Idris, K., Mohamed Shaffril, H. A., Md. Yassin, S., Abu Samah, A., Hamzah, A., Abu Samaha, B. (2016): Quality of life in rural communities: Residents living near to Tambling, Pahang and Muar Rivers, Malaysia. PloS One 11(3), 116, https://doi.org/10.1371/journal.pone.0150741.
Ismail, W. A. W., Said, I. (2015): Integrating the community in urban design and planning of public spaces: a review in Malaysian cities. Procedia - Social and Behavioral Sciences 168, 357-364, http://dx.doi.org/10.1016 /j.sbspro.2014.10.241.

Jalaladdini, S., Oktay, D. (2012): urban public spaces and vitality: a socio-spatial analysis in the streets of Cypriot towns. Procedia - Social and Behavioral Sciences 35, 664674, http://dx.doi.org/10.1016/j.sbspro.2012.02.135.

Johnson, A., Glover, T. (2013): Understanding urban public space in a leisure context. Leisure Sciences 35(2), 190197, https://doi.org/10.1080/01490400.2013.761922.

Jung, H. J., Ryu, J. H. (2015): Sustaining a Korean traditional rural landscape in the context of cultural landscape. Sustainability 7(8), 11213-11239, https://doi .org/10.3390/su70811213.

Kaźmierczak, A. (2013): The contribution of local parks to neighbourhood social ties. Landscape and Urban Planning 109(1), 31-44, https://doi.org/10.1016 /j.landurbplan.2012.05.007.

Kline, J. D. (2006): Public demand for preserving local open space. Society and Natural Resources 19(7), 645-659, https://doi.org/10.1080/08941920600742419.

Kavvakebi, L., Izadi Kharameh, H., Rahmatollah, Soleimani, R. (2012): Collective life in public green space, an attitude on socio-cultural diversity of space use, a case study of Shiraz Long Garden Linear Park. Journal of Urban Research and Planning 3(11), 97-114, https:// www.sid.ir/fa/journal/ViewPaper.aspx?id=193807.

Kurz, P. (2014): Planting sustainability? On the management of hedgerows in Alpine bocage landscapes. Conference paper. Plants in Urban Areas and Landscape, Nitra, https://doi .org/10.15414/2014.9788055212623.132-137.

Majedi, H., Rezaei, M. M, Mansouri, E. (2014): Functional interpretation of neighborhood public spaces in terms of identity. Journal of Iranian Culture Research 7(4), 39-61, https://doi.org/10.7508/IJCR.2014.28.002.

Meeus, J. H. A., Wijermans, M. P., Vroom, M. J. (1990): Agricultural landscapes in Europe and their transformation. Landscape and Urban Planning 18(3), 289-352. http://dx.doi .org/10.1016/0169-2046(90)90016-U.

Moroni, S., Chiodelli, F. (2014): Public spaces, private spaces, and the right to the city. International Journal of E-Planning Research 3(1), 51-65. https://doi .org/10.4018/ijepr.2014010105.

Nasution, A. D., Shalleh, A. Gh., Wahid, J. (2014): Livable public open space for citizen's quality of life in Medan, Indonesia. International Transaction Journal of Engineering, Management and Applied Sciences and Technologies 5(2), 131-142, http://TuEngr.com.

Orum, A. M., Neal, Z. P. (2009): Common ground? readings and reflections on public space. Routledge. https://doi .org/10.4324/9780203873960.

Song, H., Pan, M., Chen, Y. (2016): Nightlife and public spaces in urban villages: A case study of the Pearl River Delta in China. Habitat International 57, 187-204. http://dx.doi.org/10.1016/j.habitatint.2016.07.009.

Stockdale, A., Barker, A. (2009): Sustainability and the multifunctional landscape: An assessment of approaches to planning and management in the Cairngorms National Park. Land Use Policy 26(2), 479-492, http://dx.doi .org/10.1016/j.landusepol.2008.07.001. 
Tveit, M. S. (2009): Indicators of visual scale as predictors of landscape preference; a comparison between groups. Journal of Environmental Management 90(9), 2882-2888, http://dx.doi.org/10.1016/j.jenvman.2007.12.021.

Węziak-Białowolska, D. (2016): Quality of life in cities - Empirical evidence in comparative European perspective. Cities 58, 87-96, http://dx.doi .org/10.1016/j.cities.2016.05.016.

Whisler, R. L., Waldorf, B. S., Mulligan, G. F., Plane, D. A. (2008): Quality of life and the migration of the college-educated: a life-course approach. Growth and Change 39(1), 58-94, http://dx.doi.org/10.1111/j.1468-2257.2007.00405.x.

Yoon, H., Srinivasan, S. (2015): Are they well situated? Spatial analysis of privately owned public space, Manhattan, New York City. Urban Affairs Review 51(3), 358-380, http:// dx.doi.org/10.1177/1078087414552457.

Zhong, X. (2020): Research on rural cultural space reconstruction based on the theory of space production. In E3S Web of Conferences 89,1-4, https://doi .org/10.1051/e3sconf/20201890100. 